\section{Commentary: Lack of screening makes primary prevention most effective to reduce the mortality of aortic dissection}

\author{
G. Chad Hughes, MD
}

In the current issue of the Journal, Girardi and colleagues ${ }^{1}$ present an outstanding review of the current state of the science regarding the use of aortic dimensions as predictors of adverse aortic events, primarily acute type A aortic dissection (ATAD), for patients with proximal aortic disease. They conclude that the predictive value of a single metric, ie, diameter, may be insufficient to predict the occurrence of ATAD, given the fact that most patients dissect at diameters below currently recommended surgical thresholds, ${ }^{2}$ and call for further study of several more recently proposed indices such as aortic length or volume. They also point out that emerging studies examining flow dynamics and wall stress with 4-dimensional magnetic resonance imaging may prove even more reliable metrics to guide surgical intervention in the future. I concur completely with their findings and highly recommend all practitioners involved in the care of these patients read the article in its entirety, as I cannot add any additional insights that would meaningfully add to their comprehensive review. Rather, in this Commentary, I choose to focus on some other aspects of the disease (ATAD) that we as surgeons are trying to prevent with guidelines-based prophylactic surgery to highlight why more stringent guidelines or a "left-shift" 3 of intervention criteria toward smaller aortic diameters are unlikely to meaningfully impact the incidence of ATAD.

\footnotetext{
From the Division of Cardiovascular and Thoracic Surgery, Department of Surgery, Duke University Medical Center, Duke University, Durham, NC.

Disclosures: The author reported no conflicts of interest.

The Journal policy requires editors and reviewers to disclose conflicts of interest and to decline handling or reviewing manuscripts for which they may have a conflict of interest. The editors and reviewers of this article have no conflicts of interest.

Received for publication Aug 18, 2020; revisions received Sept 9, 2020; accepted for publication Sept 9, 2020; available ahead of print Sept 12, 2020.

Address for reprints: G. Chad Hughes, MD, Department of Surgery, Center for Aortic Disease, Duke University Medical Center, Box 3051 DUMC, Durham, NC 27710 (E-mail: gchad.hughes@duke.edu).

J Thorac Cardiovasc Surg 2021;161:1202-3

$0022-5223 / \$ 36.00$

Copyright (c) 2020 by The American Association for Thoracic Surgery

https://doi.org/10.1016/j.jtcvs.2020.09.031
}

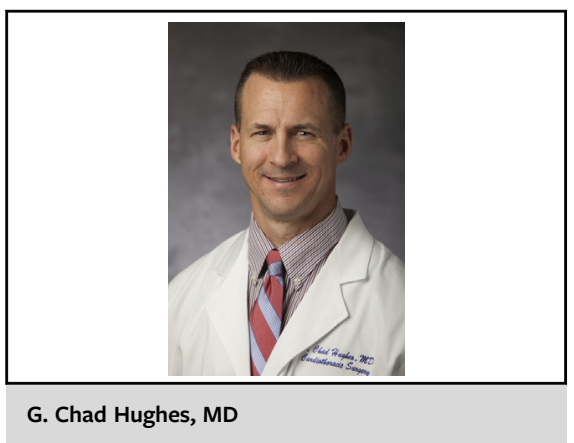

\author{
CENTRAL MESSAGE \\ Aortic dissection (AD) is a \\ disease of the medically under- \\ served. While additional metrics \\ may prevent some cases of AD, \\ any changes will have minimal \\ impact on the majority of \\ patients with AD.
}

Aortic dissection is a disease of the medically underserved. Data from our institution ${ }^{4}$ have demonstrated that $56 \%$ of patients undergoing nonelective thoracic aortic surgery, the majority of which were for aortic dissection, were underinsured. Further, underinsurance was the greatest risk factor for requiring nonelective thoracic aortic operation, likely because these patients lack access to preventative cardiovascular care as well as elective surgical care. A follow-up study using a much larger dataset of $>51,000$ patients from The Society of Thoracic Surgeons Adult Cardiac Surgery Database found similar findings, with the need for nonelective operation being greatest for uninsured patients $(72 \%)$ and lowest for privately insured patients $(37 \%))^{5}$ Numerous studies have demonstrated that uninsured patients are not only less likely than insured patients to receive adequate screening for hypertension and other cardiovascular risk factors but also less likely to receive adequate medical therapy when such conditions are diagnosed. ${ }^{6-10}$ Further, such patients are less likely to undergo screening for disease progression or be referred for elective surgery. ${ }^{9}$ Consequently, relevant to the topic of the current review by Girardi and colleagues, any changes to the current guidelines to broaden the indications for elective aortic replacement will preferentially benefit those with stable access to the health care system ${ }^{5}$ and have minimal impact on the majority of patients suffering from ATAD. 
Further, unlike abdominal aortic aneurysm, where wellestablished screening guidelines have been put forth by the US Preventive Services Task Force, ${ }^{11}$ no such recommendations exist for thoracic aortic aneurysm. This lack of an effective screening protocol is due to the need for cross-sectional imaging such as computed tomography angiography or magnetic resonance imaging, which carry not only greater health care costs but also potential risks related to radiation exposure or intravenous contrast, to reliably detect thoracic aortic disease beyond the aortic root. ${ }^{12}$ This is unfortunate, as data from large autopsy series such as The Jesse E. Edwards Registry of Cardiovascular Disease demonstrate that $>60 \%$ of cases of ATAD are not detected clinically and are first identified at autopsy, including nearly $40 \%$ of patients who die suddenly ${ }^{13}$ and therefore have no chance at surgical salvage. Further, the incidence of first diagnosis of ATAD at autopsy has not improved in the modern era, with a similar incidence between 1956-1992 and 1993-2015 in the Edwards Registry, despite the widespread availability of highly sensitive noninvasive imaging to detect thoracic aortic aneurysm since the early 1990s. ${ }^{13} \mathrm{Au}-$ topsy data also point out that the vast majority of ATAD cases $(84 \%)$ occur in patients with left ventricular hypertrophy suggestive of long-standing hypertension, ${ }^{13}$ a finding that suggests that better screening for hypertension in the population represents a meaningful opportunity to reduce the incidence of ATAD and its attendant significant immediate and unpreventable mortality risk.

To this point, another large autopsy study from Sweden spanning the years $2000-2016^{14}$ found a decreasing incidence of abdominal aortic aneurysm over time, attributable to declining smoking rates in the country, yet demonstrated that the incidence of aortic dissection remained stable over the study interval and was associated with stable high rates of hypertension and unawareness of hypertension. One of the major conclusions of the Swedish study was a call for improved primary prevention to reduce the incidence of aortic dissection and other hypertension-related diseases. This represents a significant opportunity to make a meaningful impact on ATAD-related death, as previous data demonstrate that $>50 \%$ of the worldwide population with hypertension is unaware of their diagnosis. ${ }^{15}$ Since $>60 \%$ of patients with ATAD will die before diagnosis, ${ }^{13}$ the most effective way to reduce the mortality of the disease is to prevent it from occurring via better hypertension screening and access to primary prevention for those at risk. Ultimately, primary care providers have the opportunity to save more patients from aortic dissection than we as surgeons ever will.

\section{References}

1. Girardi LN, Lau C, Gambardella I. Aortic dimensions as predictors of adverse events. J Thorac Cardiovasc Surg. 2021;161:1193-7.

2. Pape LA, Tsai TT, Isselbacher EM, Oh JK, O'Gara PT, Evangelista A, et al. Aortic diameter $>$ or $=5.5 \mathrm{~cm}$ is not a good predictor of type A aortic dissection: observations from the International Registry of Acute Aortic Dissection (IRAD). Circulation. 2007;116:1120-7.

3. Ziganshin BA, Zafar MA, Elefteriades JA. Descending threshold for ascending aortic aneurysmectomy: is it time for a "left-shift" in guidelines? J Thorac Cardiovasc Surg. 2019; 157:37-42.

4. Andersen ND, Hanna JM, Ganapathi AM, Bhattacharya SD, Williams JB, Gaca JG, et al. Insurance status predicts acuity of thoracic aortic operations. $J$ Thorac Cardiovasc Surg. 2014;148:2082-6.

5. Andersen ND, Brennan JM, Zhao Y, Williams JB, Williams ML, Smith PK, et al. Insurance status is associated with acuity of presentation and outcomes for thoracic aortic operations. Circ Cardiovasc Qual Outcomes. 2014;7:398-406.

6. Ayanian JZ, Weissman JS, Schneider EC, Ginsburg JA, Zaslavsky AM. Unmet health needs of uninsured adults in the United States. JAMA. 2000;284: 2061-9.

7. Ayanian JZ, Zaslavsky AM, Weissman JS, Schneider EC, Ginsburg JA. Undiagnosed hypertension and hypercholesterolemia among uninsured and insured adults in the Third National Health and Nutrition Examination Survey. Am J Public Health. 2003:93:2051-4.

8. Gandelman G, Aronow WS, Varma R. Prevalence of adequate blood pressure control in self-pay or Medicare patients versus Medicaid or private insurance patients with systemic hypertension followed in a university cardiology or general medicine clinic. Am J Cardiol. 2004;94:815-6.

9. Hadley J. Sicker and poorer - the consequences of being uninsured: a review of the research on the relationship between health insurance, medical care use, health, work, and income. Med Care Res Rev. 2003;60:3S-75S.

10. Moy E, Bartman BA, Weir MR. Access to hypertensive care. Effects of income insurance, and source of care. Arch Intern Med. 1995;155:1497-502.

11. US Preventive Services Task Force. Screening for abdominal aortic aneurysm: US Preventive Services Task Force Recommendation Statement. JAMA. 2019; 322:2211-8

12. Elefteriades JA, Ziganshin BA. Paradigm for detecting silent thoracic aneurysm disease. Semin Thorac Surg. 2016;28:776-82.

13. Huynh N, Thordsen S, Thomas T, Mackey-Bojack SM, Duncanson ER, Nwuado D, et al. Clinical and pathologic findings of aortic dissection at autopsy: review of 336 cases over nearly 6 decades. Am Heart J. 2019;209:108-15.

14. Acosta S, Gottsäter A. Stable population-based incidence of acute type A and B aortic dissection. Scand Cardiovasc J. 2019;53:274-9.

15. Beaney T, Schutte AE, Tomaszewski M, Ariti C, Burrell LM, Castillo RR, et al May measurement month 2017; an analysis of blood pressure screening results worldwide. Lancet Glob Health. 2018;6:e736-43. 